\title{
A Survey of Gambling Behaviors in Michigan, 2006
}

\author{
By \\ David J. Hartmann, Ph.D. \\ Department of Sociology \\ Western Michigan University
}

This study was conducted by the Kercher Center for Social Research at Western Michigan University for The Michigan Department of Community Health. Data collection was subcontracted to EPIC MRA Inc. of Lansing, Michigan. The views expressed are those of the author and do not necessarily reflect those of any of the above organizations. 


\section{Acknowledgments}

This work is based on the surveys done in 1997, 1999, and 2001 with Arlen Gullickson and the Evaluation Center at Western Michigan University. The professionalism and high quality of the work of EPIC MRA is here gratefully acknowledged, as is the assistance of Syprose Owaja on all aspects of the research design. As always, our deepest debt is to the Michigan residents who gave generously of their time and experience to produce these results.

The survey instrument was adapted from the work of Rachel Volberg who was a consultant on the 1997 project. Her published material and her willing assistance during that first project are again gratefully acknowledged. Her work since that time provides continued guidance and perspective, and remains at the core of prevalence research. 


\section{CONTENTS}

Acknowledgments $\quad$ i

Table of Contents $\quad$ ii

Introduction 1

Characteristics of the Sample $\quad 4$

$\begin{array}{ll}\text { Results } & 7\end{array}$

Detailed Results $\quad 14$

Results for Problem Gamblers $\quad 20$

$\begin{array}{ll}\text { Summary } & 23\end{array}$

Appendix A: Survey 25

Appendix B: Counties in Geographic Regions 41

References $\quad 42$ 


\section{$\underline{\text { Introduction }}$}

The 2006 Survey of Gambling Behaviors in Michigan is the fourth iteration of a project begun in 1997 and primarily designed to provide an estimate of problem gambling in the state. While there were two-year intervals between that first study and replications in 1999 and 2001, it has now been five years since a statewide prevalence estimate has been produced in Michigan. While minor changes were implemented in each iteration of the earlier studies (c.f., Hartmann and Gullickson 2001), this year’s project is, as closely as possible, a replication of the 2001 research. The most important changes made up to and including the 2001 project were: 1) inclusion of questions on Internet gambling (added in 1999) and on suicidal ideation related to gambling and use of the State Problem Gambling Help Line (added in 2001), 2) the design sampled and collected responses so as to produce samples of at least size 384 from each of five regions in the State of Michigan: The City of Detroit, the remainder of the Detroit metropolitan area, East Michigan, West Michigan, and the Upper Peninsula (see Appendix B). In 1999 the Detroit Metropolitan Region included the City and in 1997, Wayne County rather than the City was estimated separately from the rest of the Metropolitan Area. This year, 400 responses were obtained in each of the five regions.

The current design allows inference of the rate of problem gambling within each region with a reasonable degree of precision based on sampling error (plus or minus 3 percentage points $^{1}$ ) and allows combination of those regions in proportion to their contribution to the adult population of the state in an aggregate data set. As described more fully in the section called “Characteristics of the Sample," this year's state aggregate data set contains 957 interviews and therefore has precision based on sampling error of plus or minus 1.9 percentage points ${ }^{2}$ for the rate of problem gambling.

\footnotetext{
${ }^{1}$ When problem gambling is liberally estimated at $10 \%$.

${ }^{2}$ The bounds of inference are calculated as $B=z \sqrt{\frac{p q}{n}}$ where $\mathrm{B}$ is the bound plus or minus from the sample estimate, $\mathrm{p}$ is the population proportion of the event in question, $\mathrm{q}$ is $1-\mathrm{p}, \mathrm{z}$ is the $\mathrm{z}$-value for the desired confidence coefficient, and $\mathrm{n}$ is the sample size. For example; for $\mathrm{p}=.1$ and $\mathrm{n}=957$ with a confidence coefficient of .95 ( $\mathrm{z}=1.96$ ), $\mathrm{B}=.019$.
} 
A consistent challenge of prevalence studies is that, since the rate of problem gambling is low, regional and even statewide samples yield a small number of persons scoring with a problem on the South Oaks Gambling Screen (SOGS: discussed below). For obvious reasons, including the planning of helping strategies, this is an important population to sample and about which to make inference. In both 2001 and this year, additional interviewing was therefore done to increase the number of respondents scoring as a "problem” or “probable pathological gambler” on the SOGS to 200 thereby allowing more precise analysis of this important subgroup. In 2001, we used a special sample of persons with an expressed interest in gambling as a form of recreation to efficiently increase the number of responding problem or probable pathological gamblers. The non-comparability of this targeted sample with the random adult sample used for the main study made combining the problem and probable pathological gamblers from the two datasets problematic. To address this concern, this year additional sampling to obtain the needed numbers was done using the same population of adult residents of the state as was used for the main study. While this is less efficient, all 206 problem and probable pathological gamblers interviewed are now drawn from and represent the adult statewide population. Fully 118 interviews completed from this additional interviewing were added to the 88 interviews obtained from the original statewide calling.

As before, the primary aim of the survey is to establish a precise estimate of problem gambling in the population of Michigan residents 18 years and older. The 1997 study was required to establish this estimate with precision due to sampling error of no more than plus or minus 1 point (Gullickson and Hartmann 1997). This led to a design through which 3,942 responses were completed. Subsequent iterations were allowed to produce statewide estimates with slightly larger confidence bands and so allowed substantial data collection savings. The statewide samples were of size 1,211 in 2001 and 957 in 2006.

The standard in prevalence studies, including our earlier work in Michigan, is to administer the survey through a Computer Assisted Telephone Interviewing (CATI) approach utilizing a random-digit dial (RDD) telephone sample. The CATI system automates and 
documents the distribution of numbers to interviewers while also recording the disposition of each call and storing completed interviews in a database. Efficiency of administration is enhanced through automated advancing through contingency branches in the survey and data entry errors are minimized through range restrictions and similar verification checks. In our survey, for example, the SOGS score must be calculated to determine whether the section of the survey for problem gamblers should be completed. This would be very difficult to accomplish in a non-computerized format. The random digit numbers themselves are obtainable in a variety of ways but generally trade off inclusiveness for efficiency. For example, area codes and three digit prefixes are typically the starting point for randomizing the last four numbers while even potential subsets of these suffixes are systematically vetted to increase efficiency of hit rates (actually connecting to a residential number).

As documented in our earlier reports and most fully in Gullickson and Hartmann 1997, the original form of the survey instrument used in 1997 was adapted from Rachel Volberg's survey of New York State in 1996 (Volberg 1996c) and uses the South Oaks Gambling Screen (SOGS) as the basis for estimates of problem gambling. Again, only minor changes to the instrument have been made in our subsequent studies.

Since the South Oaks Gambling Screen (Lesieur \& Blume, 1987) is the basis for the prevalence estimates made in this study, the brief description offered in earlier reports is repeated here. The SOGS asks about a range of behaviors and orientations toward gambling and is highly correlated with the APA's DSM-III-R (Diagnostic and Statistical Manual of Mental Disorders, 3rd ed.-revised) criteria for pathological gambling (American Psychiatric Association, 1987). It has possible scores of 0 to 20 with 0 through 2 considered nonproblem gambling, 3 through 4 identified as "problem gambling”, and 5 or more identified as “probable pathological gambling." As is customary in current use of the SOGS, we asked each of the 20 scored questions for two time frames, “ever” and "in the past year." These give rise to a "lifetime” SOGS score and a “current” (past year) SOGS score. Since a person must score a point on the lifetime question to be asked the past year question, the lifetime score is the basis for admission to the problem 
gamblers section of the survey.

Other scales, based on the DSM-IV for example, are available. In fact, Volberg herself has regularly predicted that these other scales might come to supplant the SOGS but, as of her summary of the field in 2004 (Volberg 2004), that had not yet happened. So, because so large a preponderance of geographic prevalence studies (including studies at the state and Canadian Province level) used the SOGS, including the 1997, 1999, and 2001 Michigan studies, we retain it here.

\section{Characteristics of the Sample}

EPIC/MRA reports that in the geographic sampling used to produce the regional and statewide estimates, a total of 2,000 responses were obtained with a refusal rate of just over $71 \%$. This rate for the main study is higher than the 65\% rate obtained in 2001 but is well within the expected range for telephone surveys over the past five years. In fact, a recent study in British Columbia reported a similar 73\% refusal rate and also pointed out that a review of national omnibus surveys showed an average refusal rate of 77\% (British Columbia 2003). Groves et al (2004) report that that even the Behavioral Risk Factor Surveillance System, one of the best funded and prestigious telephone based household surveys, showed an increase in median non-response ${ }^{3}$ across states from about 30\% in 1991 to almost 50\% by 2001 (p. 187). Since most statewide gambling prevalence studies were done some time ago, their refusal rates are a bit lower. The last two state-wide surveys we reviewed in 2001 showed a 64 percent rate in New York in 1996 and a 60 percent rate for Louisiana in 1995 at about the time we achieved the 65\% rate in Michigan. Note that our earlier studies also had somewhat better refusal rates: 57 percent rate in 1997 and 55 percent in 1999. It is reassuring but not sufficient that several studies (British Columbia 2003, Volberg 2004) point out that the quality of prevalence rate estimates seem to be robust with respect to refusal rates.

Since samples sizes of 400 were collected by region to allow inference at acceptable

\footnotetext{
${ }^{3}$ Refusals are a component, generally the largest and fastest growing one, in response rates.
} 
levels for each part of the state, a representative statewide sample could not be a simple aggregation of the regions. A weighting procedure was used to produce a statewide sample of size 957 that is weighted to represent the adult population of Michigan at the county level. This resulted in an error band at a 95\% confidence level for problem gambling rates with a precision of plus or minus 1.9 points based on sampling error (the band was plus or minus 1.7 points in 2001). The weighted sample includes 403 cases from the Metropolitan Detroit sample, 179 from the east counties, 251 from the west, 35 from the U.P., and 89 from the City of Detroit. That weighted sample is used throughout this report as the "state sample."

Sampling variation due to sample size is only one source of error in inference. The real concern is response bias and a standard check on this, particularly in the presence of high refusal rates, is to directly compare the obtained demographic characteristics of the sample against other estimates of those population characteristics in which one has some confidence. Table 1 does this for the statewide weighted sample against the 2000 Census figures for the state.

In reviewing this comparison, it is important to note that telephone surveys are used for prevalence studies because, despite reduced response rates, they can produce an efficient tradeoff of cost and response bias. Random digit dial (RDD) approaches, in particular, are preferred because they address the most obvious sources of bias in telephone sampling, access to unlisted numbers. Nevertheless, the RDD telephone survey has known weaknesses. First, most survey organizations exclude cell phones. There is an increasing percentage of the population that does not have a landline (perhaps as high as 5-10\%). Also, as discussed in earlier reports, telephone surveys in general often under-represent males, poor people, and younger respondents and therefore tend to under-represent characteristics associated with male sex, low income, and youth. Several factors are likely to be in play. First, men are less likely to answer the phone when a woman also resides there. Second, the poor simply are less likely to own a phone. Third, participation rates in survey research are directly related to education. Furthermore, poorer families and young householders may be less likely to have an adult at home in the evening when the bulk of contact attempts are made (due to one adult households and late shift 
work). Poor households also tend to have a younger age structure, which is also related to presence in the home and willingness to participate. In any event, most telephone surveys expect to under-represent men, the young, the poor, and the less educated and consequently black and central-city residents as well.

Each recent statewide gambling study we reviewed reported these biases, especially with regard to education and income. A standard correction for each response rate variation is to weight the underrepresented category for analyses. Most of the statewide gambling studies did not do this, however. In her Iowa report, Volberg contends that, “To maintain comparability with results from the 1989 survey from Iowa, as well as with results from surveys in other United States jurisdictions, it was deemed advisable to caution readers regarding these prevalence estimates rather than weight the results from the 1995 sample.” (Volberg 1995b, p. 5). We followed this precedent in past studies and do so again here. In the 1997 report, we produced both weighted and un-weighted estimates. Weighting did affect estimates of gambling problems in Michigan, though the magnitudes tended to be of a half a percentage point or less. As explained below, it is important to remember that response bias, to the extent that it is present in all gambling prevalence surveys of this type, almost certainly works to produce underestimation relative to the actual rates of gambling and problem gambling in the population.

Table 1 shows the characteristics of respondents to the 2006 Michigan survey and of Census descriptors for Michigan's adult population. As expected, the statewide sample underrepresents males, minorities, and the youngest, least educated, and poorest residents of the state. This selection bias is largest for gender though using a weight for gender had only a modest effect on the statewide prevalence rate (about a tenth of a percentage point). As before, weighted estimates are not reported because of their small effect and the lack of such practice in other studies. The final reason for using un-weighted estimates is that the assumptions of weighting (principally that non-respondents of a particular demographic category are well represented by respondents of that category) are rarely justified. 
Table 1. Percent of the Sample in Demographic Categories Compared to Those of the 2000 Census Population Aged 18+

\begin{tabular}{|l|l|l|}
\hline & $\begin{array}{l}\text { Statewide } \\
\text { Sample }\end{array}$ & $\begin{array}{l}2000 \\
\text { Census }\end{array}$ \\
\hline $\mathrm{N}$ & 957 & $7,342,677$ \\
\hline Gender & & \\
\hline Male & 42.6 & 49.0 \\
\hline Female & 57.4 & 51.0 \\
\hline Race/Ethnicity & & \\
\hline White/Caucasian & 85.9 & 80.2 \\
\hline $\begin{array}{l}\text { Black/African } \\
\text { American }\end{array}$ & 10.7 & 14.2 \\
\hline Other & 3.3 & 5.6 \\
\hline & & \\
\hline Hispanic & 2.1 & 3.3 \\
\hline Age & & \\
\hline 18-20 & 1.6 & 5.8 \\
\hline $21-64$ & 71.3 & 77.6 \\
\hline 65 or older & 27.1 & 16.6 \\
\hline Education & & \\
\hline$<$ High School & 6.8 & 16.6 \\
\hline High School/GED & 30.6 & 31.3 \\
\hline Some College/Assoc. & 31.8 & 30.3 \\
\hline Bachelors Degree & 14.9 & 13.7 \\
\hline Grad.Study/Degree & 15.8 & 8.1 \\
\hline Household Income & & \\
\hline \$25,000 or less & 23.1 & 26.5 \\
\hline \$25,001 to \$50,000 & 30.5 & 28.9 \\
\hline \$50,001 to \$100,000 & 33.4 & 32.0 \\
\hline \$100,001 or more & 13.0 & 12.7 \\
\hline & & \\
\hline
\end{tabular}

\section{$\underline{\text { Results }}$}

As before, the main variables of interest in this year's survey are the estimated rates of problem and probable pathological gambling as derived from the South Oaks Gambling Screen (SOGS). Table 2 presents the number and percentage of respondents who ever gambled and gambled in the past year as well as the unweighted SOGS estimates for lifetime and current (last 12 month) periods. 
The percent who ever gambled is $84.4 \%$, which is very close to the rate in 2001 (85.3\%) and is almost identical to the 84.5\% rate found with a sample of almost 4,000 persons in 1997 . The rate in 1999 was just a bit higher at $88.9 \%$. The basic conclusion is therefore one of stability over the four surveys. The result for past year gambling is $70.9 \%$ this year compared to $71.9 \%$ in 2001, 76.9\% in 1997 and $77.6 \%$ in 1999 . All of these rates are within the expected range established by previous statewide surveys.

Table 2 also presents the SOGS scores for the state and for geographic regions of the state defined by Detroit and the state's counties (see Appendix B). SOGS scores are reported in the table both for the "problem" and "probable pathological” categories. In this report, the two percentages are often combined into a single SOGS score for “problem gamblers.” The state estimate for the "Lifetime SOGS" is 4.1 with an estimate of 2.0 for the "Current SOGS." These figures are statistically indistinguishable from those obtained in 2001, 1999, and 1997 though the 1997 rates were highest at 5.2 and 3.4. Recall that sampling error is approximately 1.9 points above and below the SOGS score so an actual state SOGS score as low as 2.2 or as high as 6.0 is consistent with these survey results. ${ }^{2}$ Another way to think about how close these estimates are is to realize that the "Lifetime" estimate in 2006, for example, would exactly match the 2001 estimate if we had completed 4 more interviews with persons in the problem categories out of the 957 in the sample. A similar difference was found between the 2001 and 1999 estimates.

\footnotetext{
${ }^{2}$ It is, of course, standard practice to use the sample proportion to substitute for the population parameter $\mathrm{p}$ in the standard error calculation. The use of the sample proportion is an expedient that is appropriate under most conditions. Here it would yield an interval from 2.8 to 5.4. On the other hand, an important rationale for using an alternative to the sample proportion is that any sampling error in the point estimate is reintroduced by using that point estimate again in the calculation of the standard error (Blalock, 1979, pp. 214-215). As we argue below (p. 11), in our case, we believe the sample estimates are low. With proportions we have the additional attraction of more conservative intervals as we move toward $\mathrm{p}=.5$. Making wider confidence intervals warns users of this report that there may not be as much actual precision in our estimates as the standard construction would suggest. The use of $\mathrm{p}=.1$ in the construction of the standard error for the SOGS estimates is a compromise that we believe is conservative relative to the use of the sample proportion obtained. The most conservative interval would result from using a value of $\mathrm{p}=.5$ but that is unrealistic given the literature and our own estimates over three studies. Our approach may yield an interval that may actually provide greater than $95 \%$ confidence (more properly, that more than $95 \%$ of the time intervals constructed by this procedure will include the parameter). That is the effect if, in fact, the interval is wider than it needed to be. The same reasoning underlies the use of $p=.5$ for the calculation of the standard errors in Table 4. This value is explicitly too conservative for the rare behaviors (footnote on p. 14) but is pretty good for the common behaviors and, again, warns against over interpretation of the estimates.
} 
Our studies in 1997 and 1999 suggested higher rates in the Detroit area but did not allow an estimate specific to the city. Lifetime rates were 8.1 for Wayne County (including the City) in 1997 and 6.4 for Metropolitan Detroit (including the City) in 1997. In 2001, measurement for the City of Detroit was made directly and the estimate was 11.4. This year's estimate for the City proper is statistically identical at 10.8 .

This year's lifetime rates in the other geographic regions were also similar to those seen in the 1999 and 2001 iterations of this research, which used comparable sample sizes and county aggregations. The East region scored at 2.6 compared to 4.0 in 2001 and 4.5 in 1999 . The West region scored at 2.3 compared to 2.5 in 2001 and 2.9 in 1999. The Upper Peninsula scored at 2.6 compared to 5.2 in 2001 and 5.1 in 1999. Metropolitan Detroit was not geographically comparable in 1999 or before but was $4.3 \%$ this year and 3.5\% in 2001. Since sample sizes for the regions only allowed confidence bands of plus or minus 3 points, even the UP rate was not statistically different from previous years. 
Table 2. Gambling Prevalence for Michigan and South Oaks Gambling Screen (SOGS) Scores for Michigan and Geographic Regions of the State

A. State of Michigan

\begin{tabular}{lr|ll}
\hline \multicolumn{2}{l|}{ Gambling Experiences } & $N$ & $\%$ \\
\hline \multicolumn{1}{l}{ Ever } & Yes & 808 & 84.4 \\
& No & 150 & 15.6 \\
\multirow{4}{*}{ Past Year } & & & \\
& Yes & 678 & 70.9 \\
& No & 279 & 29.2 \\
\hline
\end{tabular}

\begin{tabular}{l|llllll}
\hline & \multicolumn{3}{|c}{ Lifetime SOGS Score } & \multicolumn{3}{c}{ Current SOGS Score } \\
\hline & $\mathbf{0 - 2}$ & $\mathbf{3 - 4}$ & $\mathbf{5 +}$ & $\mathbf{0 - 2}$ & $\mathbf{3 - 4}$ & $\mathbf{5 +}$ \\
$\mathrm{N}$ & 919 & 26 & 13 & 938 & 11 & 8 \\
Percent & 95.9 & 2.7 & 1.4 & 98. & 1.1 & 0.9 \\
Total Problem & \multicolumn{7}{c}{4.1} & & & 2.0 \\
Gamblers & \multicolumn{7}{c}{4} & & & 2.0 \\
\hline
\end{tabular}

Estimated total problem gamblers (based on Census count of 7,342,677 people 18+)

Point estimate: 301,050 Lifetime

146,854 Current.

95\% confidence interval $\quad(161,539-440,561)$

$(7,343-286,364)$

B. Geographic Regions of Michigan*

\begin{tabular}{|c|c|c|c|c|c|c|c|}
\hline \multirow[t]{2}{*}{ Region } & \multicolumn{3}{|c|}{ Lifetime SOGS Score, \% } & \multicolumn{3}{|c|}{ Current SOGS Score, \% } & \multirow[t]{2}{*}{$N$} \\
\hline & $0-2$ & $3-4$ & $5+$ & $0-2$ & $3-4$ & $5+$ & \\
\hline Detroit & 89.3 & 4.8 & 6.0 & 93.8 & 2.8 & 3.5 & 400 \\
\hline Detroit Metro. & 95.8 & 3.3 & 1.0 & 98.3 & 1.0 & 0.8 & 400 \\
\hline East Michigan & 97.5 & 1.8 & 0.8 & 98.8 & 1.0 & 0.3 & 400 \\
\hline West Michigan & 97.8 & 1.5 & 0.8 & 98.7 & 0.8 & 0.5 & 400 \\
\hline Upper Peninsula & 97.5 & 1.3 & 1.3 & 98.3 & 0.8 & 1.0 & 400 \\
\hline
\end{tabular}

Estimated Adult Problem Gamblers for Regions Based on 2000 Census

\begin{tabular}{|l|c|c|c|c|}
\hline Region & \multicolumn{2}{|l|}{$\begin{array}{l}\text { Lifetime SOGS Score, } \\
\text { Population Estimates }\end{array}$} & \multicolumn{2}{l|}{$\begin{array}{l}\text { Current SOGS Score, } \\
\text { Population Estimates }\end{array}$} \\
\hline & $\mathbf{3 - 4}$ & $\mathbf{5 +}$ & $\mathbf{3 - 4}$ & $\mathbf{5 +}$ \\
\hline Detroit & 31,368 & 39,210 & 18,298 & 22,872 \\
\hline Detroit Metro. & 98,135 & 29,738 & 29,738 & 23,790 \\
\hline East Michigan & 29,474 & 13,099 & 16,374 & 4,912 \\
\hline West Michigan & 27,425 & 14,627 & 14,627 & 9,142 \\
\hline Upper Peninsula & 3,246 & 3,246 & 1,997 & 2,497 \\
\hline
\end{tabular}

*Note that the rates and associated numbers of problem gamblers by region are based on the full samples of 400 for each region. These are more reliable but slightly different than the smaller samples by region used for the statewide estimates (recall the total weighted statewide sample is 957). Therefore, the totals added across regions in Table 2B would be slightly different than the statewide totals reported out of Table 2A. 
In general, the rates for geographic regions, based on samples of size 400 (error estimated at plus or minus 3 points) are less precise than the estimates for the state sample derived from a sample size of 957 (error estimated at plus or minus 1.9 points).

An important result illustrated in Table 2A is that, based on the 2000 census count of 7,342,677 residents 18 years of age and older in Michigan, the SOGS survey estimates that about 300,000 adult Michigan residents have a lifetime gambling problem, with 103,000 of those estimated to have a probable pathological condition as indicated by a score of 5 or more on the Lifetime SOGS. Again, these figures are statistically identical to the 1999 and 2001 estimates. Similarly, the survey results indicate that 147,000 Michigan adults currently have a gambling problem, more than 66,000 of those having a severe or "probable pathological" problem.

These figures represent the best available single number estimate (“point estimate”) but the actual population value most likely falls near but not precisely at these numbers. If we argue that the sample is randomly representative of the adult Michigan population, then there is a 95\% probability (95\% confidence) that the actual number of lifetime problem gamblers in Michigan is between 162,000 and 441,000. Past year, problem gamblers probably (again, with 95\% confidence) number between 7,300 and 286,000. ${ }^{3}$ These “confidence intervals” are a more useful quantification than the point estimates because they take into account the sampling error of estimate expected with a sample of this size. The last panel of Table 2 shows the adult population estimated to have a gambling problem by region based on the SOGS rates and the 2000 Census. Again, these estimates are less precise than the state estimates.

Finally, both the point estimates and the confidence intervals built around them probably underestimate the actual number of problem gamblers by the SOGS criteria. There are two reasons; both occur because the sample is not fully randomly representative of the population. First, recall that telephone interviews tend to under-represent the young and the poor who may

\footnotetext{
${ }^{3}$ Recall the range of persons with lifetime and past year problems would be narrower, both here and in the 1999 and 2001 estimates, if the sample proportions were used in the construction of the confidence intervals. This year, for example, the population estimates would range from 206,000 to 397,000 adult Michigan residents with a lifetime gambling problem and 81,000 to 213,000 with a past year problem.
} 
have higher rates of problem gambling. Second, the population figures we used, of course, do not include anyone under the age of 18 who might have a problem since they were excluded from the survey. Our interviews and focus groups in 1997, as well as the survey questions that ask respondents when they started gambling, all suggest a substantial prevalence of gambling among teenagers.

As in 1997 and 1999, 2001 Michigan estimates are well within the range found in other states. Table 3 (derived from Volberg 1996a) summarizes this comparison both chronologically and by magnitude of the lifetime rate of problem and probable pathological gambling.

The final panel shows the four sets of Michigan estimates graphically.

Table 3. Estimates of Statewide Prevalence of Problem and Probable Pathological Gambling

\section{Lifetime Current}

Prevalence (\%) Prevalence (\%)

Panel A. Chronological Order

\begin{tabular}{llll}
\hline 1986 & New York & 4.2 & \\
1988 & New Jersey & 4.2 & \\
1988 & Maryland & 3.9 & \\
1989 & Massachusetts 4.4 & & \\
1989 & Iowa & 1.7 & \\
1990 & California & 4.1 & 1.6 \\
1990 & Minnesota & & 1.4 \\
1991 & South Dakota & 2.8 & \\
1991 & Connecticut & 6.3 & 2.5 \\
1992 & Texas & 4.8 & 2.8 \\
1992 & Washington & 5.1 & 2.2 \\
1992 & Montana & 3.6 & 2.0 \\
1992 & North Dakota & 3.5 & 1.2 \\
1993 & South Dakota & 2.3 & 2.3 \\
1994 & Georgia & 4.4 & 3.2 \\
1994 & Minnesota & & 4.8 \\
1995 & Louisiana & 7.0 & 3.3 \\
1995 & Iowa & 5.4 & 3.6 \\
1996 & New York & 7.3 & 3.4 \\
1997 & Michigan & 5.2 & 3.2 \\
1999 & Michigan & 4.9 & 2.8 \\
2001 & Michigan & 4.5 & 2.0 \\
2006 & Michigan & 4.1 &
\end{tabular}


Panel B. Ranked by Lifetime Prevalence

$\begin{array}{llll}1996 & \text { New York } & 7.3 & 3.6 \\ 1995 & \text { Louisiana } & 7.0 & 4.8 \\ 1991 & \text { Connecticut } & 6.3 & \\ 1995 & \text { Iowa } & 5.4 & 3.3 \\ 1997 & \text { Michigan } & 5.2 & 3.4 \\ 1992 & \text { Washington } & 5.1 & 2.8 \\ 1999 & \text { Michigan } & 4.9 & 3.2 \\ 1992 & \text { Texas } & 4.8 & 2.5 \\ 2001 & \text { Michigan } & 4.5 & 2.8 \\ 1989 & \text { Massachusetts } & 4.4 & \\ 1994 & \text { Georgia } & 4.4 & 2.3 \\ 1986 & \text { New York } & 4.2 & \\ 1988 & \text { New Jersey } & 4.2 & \\ 2006 & \text { Michigan } & 4.1 & \\ 1990 & \text { California } & 4.1 & \\ 1988 \text { Maryland } & 3.9 & 2.2 \\ 1992 & \text { Montana } & 3.6 & 2.0 \\ 1992 & \text { North Dakota } & 3.5 & 1.4 \\ 1991 & \text { South Dakota } & 2.8 & 1.2 \\ 1993 \text { South Dakota } & 2.3 & \\ 1989 & \text { Iowa } & 1.7 & \end{array}$

Panel C. Graph of Michigan Estimates

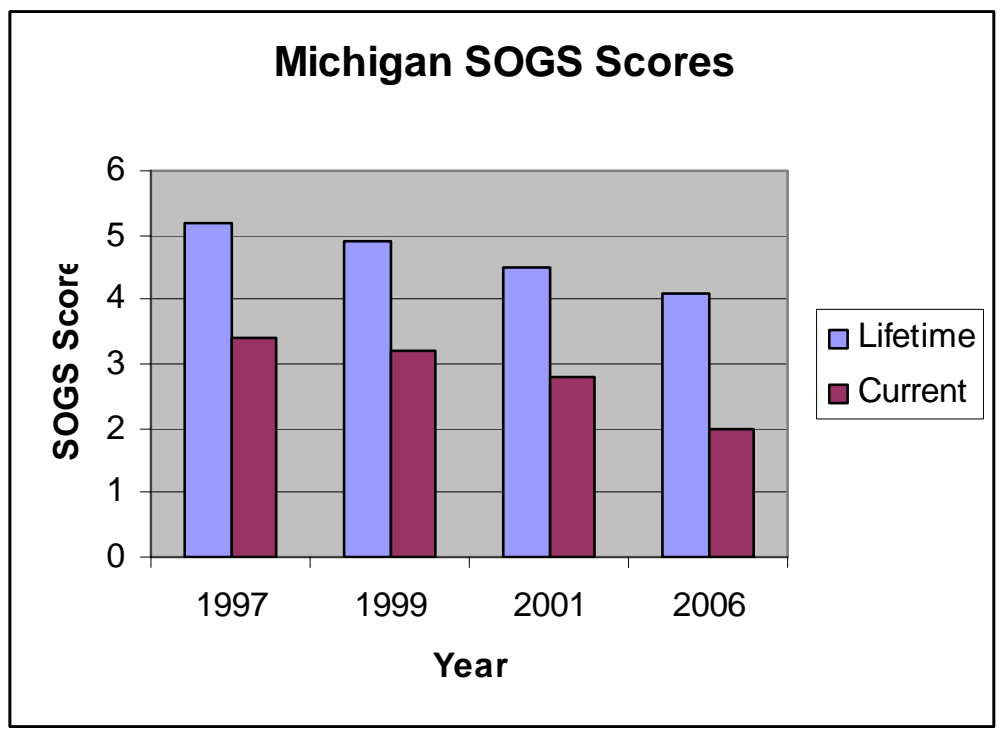




\section{Detailed Results}

Table 4 shows the rates of participation for each of the thirteen types of gambling included in the survey. Recall that respondents were asked whether they had ever participated in each activity and whether they had done so during the past year. Both responses are provided in Table 4, as are the participation rates broken out by sex and by race. Confidence intervals are also built around the total prevalence rates for both lifetime and past year participation ${ }^{4}$.

As expected, the highest rates of participation were for legal activities including the lottery and casinos. For the "ever” (lifetime) participated questions, men had statistically higher rates of participation than women in nine of the thirteen activities: lottery, sports betting, horse/dog racing, playing the numbers, betting on non-casino dice, cards and video poker, betting on one's own performance in games of skill, office pools, stocks and commodities, and other (not specified) gambling. Women did not have statistically higher rates of participation for any form of lifetime gambling. In all cases, a chi square test for independence was used. This approach is identical to a t test for the difference in two proportions (gender) and provides a single summary measure for the three proportions comparisons for race. Fisher's Exact Test was used for two by two tables with small cell frequencies.

For the "past year” activities, men were statistically higher on those same gambling types except for horse/dog racing. Women had statistically higher rates only for bingo "in the past year.” Black respondents were statistically less likely to have "ever” participated in charitable group events, office pools and 50/50 raffles, and stocks/commodities markets. For the "past year” they were less likely to have participated in charitable group events and in stocks and commodities markets. Small expected cell frequencies prevented tests of race differences for five of the thirteen gambling activities for the "ever" questions and eight of the thirteen for the "past year” questions.

If the "other" race category is dropped from the tests (only 31 cases are in that category in the statewide sample), we obtain both fewer tables with small expected cell frequencies and

\footnotetext{
${ }^{4}$ We conservatively used an estimated 50\% participation rate for each activity, thereby giving the largest possible estimate of error and confidence interval.
} 
we get 2x2 tables which can be tested with Fisher's Exact Test even when small expected frequencies remain. For both the lifetime (“ever”) and the past year activities, significant differences are now obtained for illegal numbers games where blacks are more likely to participate.

Table 4. Gambling Participation Rates by Type of Gambling, Sex, and Race

A. Ever Participated

\begin{tabular}{|c|c|c|c|c|c|c|c|}
\hline $\begin{array}{l}\text { Type of } \\
\text { Gambling }\end{array}$ & Total & $\begin{array}{l}95 \% \\
\text { Confid. } \\
\text { Interval }\end{array}$ & Gender & & Race/L & icity & \\
\hline Lottery & 71.5 & $68.3-74.7$ & $\begin{array}{l}\text { Male } \\
75.6\end{array}$ & $\begin{array}{l}\text { Female } \\
68.6^{*}\end{array}$ & $\begin{array}{l}\text { White } \\
72.1\end{array}$ & $\begin{array}{l}\text { Black } \\
70.3\end{array}$ & $\begin{array}{l}\text { Other } \\
64.5\end{array}$ \\
\hline $\begin{array}{l}\text { Charitable Group } \\
\text { Events }\end{array}$ & 40.8 & $37.6-44.0$ & 39.4 & 42.0 & 42.4 & 26.5 & $41.9 * *$ \\
\hline Sports Events & 19.8 & $16.6-23.0$ & 28.0 & $13.8 * *$ & 20.6 & 14.9 & 9.4 \\
\hline $\begin{array}{l}\text { Horse/Dog } \\
\text { Racing }\end{array}$ & 25.3 & $22.1-28.5$ & 28.7 & $23.0^{*}$ & 26.2 & 20.6 & 16.1 \\
\hline Numbers Game & 6.3 & $3.1-9.5$ & 10.0 & $3.7 * *$ & 4.9 & 17.8 & $6.7 \wedge$ \\
\hline Casinos & 64.8 & $61.6-68.0$ & 66.0 & 64.1 & 65.8 & 59.8 & 53.1 \\
\hline $\begin{array}{l}\text { Non-charitable } \\
\text { Bingo }\end{array}$ & 11.2 & $8.0-14.4$ & 9.8 & 12.4 & 11.2 & 10.9 & $15.6^{\wedge}$ \\
\hline $\begin{array}{l}\text { Non-casino } \\
\text { Events }\end{array}$ & 13.1 & 9.9-16.3 & 19.8 & $8.2 * *$ & 12.9 & 12.7 & $19.4^{\wedge}$ \\
\hline Games of skill & 17.5 & $14.3-20.7$ & 29.3 & $8.9 * *$ & 17.2 & 19.8 & 16.1 \\
\hline $\begin{array}{l}\text { Office Pools \& } \\
\text { 50/50 Raffles }\end{array}$ & 46.0 & $42.8-49.2$ & 52.5 & $41.4^{* *}$ & 48.0 & 31.7 & $41.9 * *$ \\
\hline $\begin{array}{l}\text { Internet } \\
\text { Gambling Sites }\end{array}$ & 1.0 & $0.0-4.2$ & 1.2 & 0.7 & 0.7 & 2.0 & $3.2^{\wedge}$ \\
\hline $\begin{array}{l}\text { Stocks/Commodi } \\
\text { ties Markets }\end{array}$ & 27.9 & 24.7-31.1 & 33.3 & $23.9 * *$ & 30.5 & 8.9 & $23.3 * *$ \\
\hline Other & 2.7 & $0.0-5.9$ & 4.2 & $1.6^{*}$ & 2.5 & 4.0 & $3.1^{\wedge}$ \\
\hline
\end{tabular}


B. Participated During the Last Year

\begin{tabular}{|c|c|c|c|c|c|c|c|}
\hline $\begin{array}{l}\text { Type of } \\
\text { Gambling }\end{array}$ & Total & $\begin{array}{l}95 \% \\
\text { Confid. } \\
\text { Interval }\end{array}$ & Gender & & Race/l & icity & \\
\hline & & & Male & Female & White & Black & Other \\
\hline Lottery & 50.6 & 47.4-53.8 & 55.2 & $47.4^{*}$ & 50.0 & 52.9 & 53.1 \\
\hline $\begin{array}{l}\text { Charitable Group } \\
\text { Events }\end{array}$ & 25.6 & $22.4-28.8$ & 24.6 & 26.4 & 27.0 & 13.7 & $28.1^{*}$ \\
\hline Sports Events & 11.0 & $7.8-14.2$ & 15.5 & $7.8^{* *}$ & 11.6 & 9.8 & $3.2^{\wedge}$ \\
\hline $\begin{array}{l}\text { Horse/Dog } \\
\text { Racing }\end{array}$ & 2.6 & $0.0-5.8$ & 3.4 & 2.0 & 2.6 & 2.9 & $0.0^{\wedge}$ \\
\hline Numbers Game & 3.0 & $0.0-6.2$ & 4.9 & $1.6^{* *}$ & 2.6 & 6.9 & $0.0^{\wedge}$ \\
\hline Casinos & 34.0 & $30.8-37.2$ & 34.5 & 33.7 & 34.3 & 33.3 & 35.5 \\
\hline $\begin{array}{l}\text { Non-charitable } \\
\text { Bingo }\end{array}$ & 4.1 & $0.9-7.3$ & 2.5 & $5.3^{*}$ & 4.2 & 4.0 & $3.2^{\wedge}$ \\
\hline $\begin{array}{l}\text { Non-casino } \\
\text { Events }\end{array}$ & 7.7 & $4.5-10.9$ & 11.1 & $5.3^{* *}$ & 7.7 & 6.9 & $12.9^{\wedge}$ \\
\hline Games of skill & 8.8 & $5.6-12.0$ & 15.7 & $3.8^{* *}$ & 8.2 & 11.8 & $12.9^{\wedge}$ \\
\hline $\begin{array}{l}\text { Office Pools \& } \\
\text { 50/50 Raffles }\end{array}$ & 24.2 & $21.0-27.4$ & 27.7 & $21.8 *$ & 25.0 & 16.7 & 25.8 \\
\hline $\begin{array}{l}\text { Internet } \\
\text { Gambling Sites }\end{array}$ & 0.7 & $0.0-3.9$ & 1.0 & 0.5 & 0.6 & 1.0 & $3.2^{\wedge}$ \\
\hline $\begin{array}{l}\text { Stocks/Commodi } \\
\text { ties Markets }\end{array}$ & 19.3 & $16.1-22.5$ & 23.2 & $16.6^{*}$ & 21.6 & 5.9 & $9.7^{* *}$ \\
\hline Other & 1.2 & $0.0-4.4$ & 2.2 & $0.5^{*}$ & 1.2 & 2.0 & $0.0^{\wedge}$ \\
\hline
\end{tabular}

$*^{*}$ chi square test significant at $.05 \quad{ }^{* *}$ chi square test significant at .01

$\wedge 3$ by 2 table with at least one expected cell frequency less than five

Table 5 shows variation in SOGS scores for lifetime and current periods by categories of the demographic variables. Although the statewide rates are precise and stable relative to the 1997, 1999, and 2001 surveys, the rates for demographic subgroups are based on small samples. As we said in each of the previous two reports, "they should be read as indicators of potentially important variation rather than precise estimates of incidence. On a technical level, the same point is evidenced in the small cell frequencies for the crosstabulations. Tests of significance therefore have little statistical power and were not computed.” 
Table 5. Percent in SOGS Grouping by Demographic Categories

\begin{tabular}{|c|c|c|c|c|c|c|}
\hline & \multicolumn{3}{|c|}{ Lifetime SOGS Score } & \multicolumn{3}{|c|}{ Past Year/Current SOGS Score } \\
\hline & $0-2$ & $3-4$ & $5+$ & $0-2$ & $3-4$ & $5+$ \\
\hline \multicolumn{7}{|l|}{ Gender (n=957) } \\
\hline Male $(n=407)$ & 97.3 & 1.5 & 1.2 & 98.5 & 0.7 & 0.7 \\
\hline Female $(n=550)$ & 94.7 & 3.6 & 1.6 & 97.4 & 1.5 & 1.1 \\
\hline \multicolumn{7}{|l|}{ Race $(n=946)$} \\
\hline White $(n=814)$ & 96.8 & 2.6 & 0.6 & 98.8 & 1.0 & 0.2 \\
\hline Black $(n=101)$ & 89.1 & 3.0 & 7.9 & 92.2 & 2.0 & 5.9 \\
\hline Other $(n=31)$ & 96.8 & 3.2 & 0.0 & 96.9 & 3.1 & 0.0 \\
\hline \multicolumn{7}{|l|}{ Age $(n=943)$} \\
\hline $18-29(n=60)$ & 90.0 & 6.7 & 3.3 & 95.0 & 3.3 & 1.7 \\
\hline $30-49(n=298)$ & 95.6 & 3.0 & 1.3 & 98.0 & 1.3 & 0.7 \\
\hline $50-64(n=329)$ & 95.7 & 2.7 & 1.5 & 97.6 & 1.5 & 0.9 \\
\hline $65+(n=256)$ & 98.0 & 1.2 & 0.8 & 99.6 & 0.0 & 0.4 \\
\hline \multicolumn{7}{|l|}{ Education $(n=950)$} \\
\hline$<$ High School $(\mathrm{n}=64)$ & 92.2 & 6.3 & 1.6 & 95.4 & 3.1 & 1.5 \\
\hline $\begin{array}{r}\text { High School/GED } \\
(\mathrm{n}=292)\end{array}$ & 94.5 & 3.4 & 2.1 & 97.2 & 1.4 & 1.4 \\
\hline $\begin{array}{r}\text { Some College/Assoc } \\
(\mathrm{n}=302)\end{array}$ & 96.4 & 2.3 & 1.3 & 98.0 & 1.0 & 1.0 \\
\hline $\begin{array}{r}\text { Bachelors Degree } \\
(\mathrm{n}=142)\end{array}$ & 97.9 & 2.1 & 0.0 & 99.3 & 0.7 & 0.0 \\
\hline $\begin{array}{r}\text { Grad. Study/Degree } \\
(\mathrm{n}=150)\end{array}$ & 97.3 & 1.3 & 1.3 & 99.3 & 0.7 & 0.0 \\
\hline \multicolumn{7}{|l|}{ Income $(n=730)$} \\
\hline $\begin{array}{r}\$ 25,000 \text { or less } \\
(\mathrm{n}=169)\end{array}$ & 92.9 & 4.7 & 2.4 & 97.6 & 1.2 & 1.2 \\
\hline $\begin{array}{r}\$ 25,001-\$ 50,000 \\
(\mathrm{n}=223)\end{array}$ & 97.3 & 1.3 & 1.3 & 98.7 & 0.4 & 0.9 \\
\hline $\begin{array}{r}\$ 50,001-\$ 100,000 \\
(\mathrm{n}=244)\end{array}$ & 95.5 & 2.5 & 2.0 & 97.1 & 1.2 & 1.6 \\
\hline $\begin{array}{r}\$ 100,001 \text { or more } \\
(\mathrm{n}=94)\end{array}$ & 97.9 & 2.1 & 0.0 & 97.9 & 2.1 & 0.0 \\
\hline
\end{tabular}

As in earlier reports, age and race appear to have some correlation to incidence of higher scores on the SOGS but it is clear that no age, race, gender, education, or income group is immune to the risk of gambling problems.

Table 6 displays the current (past year) SOGS distribution for those who participated in each listed types of gambling activities at least once in the past year. While small numbers of respondents for particular gambling activities make several of the estimates unreliable, broad comparisons may be instructive, especially when trends hold over time. For example, as in our past surveys, 95 percent or more of those who played the lottery scored as nonproblem gamblers on the past year's SOGS. Similarly, 95\% of people who bet at casinos in the past year scored as 
nonproblem gamblers.

Table 6. Percent Distribution of Current SOGS Score by Gambling Type in the Past Year

\begin{tabular}{l|llll}
\hline & \multicolumn{4}{|c}{ Past Year/Current SOGS Score } \\
\hline Type of Gambling & $\mathrm{n}$ & $0-2$ & $3-4$ & $5+$ \\
Lottery & 483 & 96.3 & 2.3 & 1.4 \\
Charitable Group & 244 & 97.1 & 2.0 & 0.8 \\
Events & & & & \\
Sports Events & 105 & 97.1 & 1.9 & 1.0 \\
Horse/Dog Racing & 24 & 95.8 & 0.0 & 10.3 \\
Numbers Game & 29 & 86.2 & 3.4 & 1.9 \\
Casinos & 324 & 95.4 & 2.8 & 5.0 \\
Non-charitable Group & 40 & 87.5 & 7.5 & 2.7 \\
Events & & & & 2.4 \\
Non-casino Events & 73 & 93.2 & 4.1 & 1.3 \\
Games of Skill & 84 & 95.2 & 2.4 & 0.0 \\
Office Pools \& 50/50 & 231 & 97.0 & 1.7 & 0.0 \\
Raffles & & & & \\
Internet Gambling Sites & 7 & 100.0 & 0.0 & 0.0 \\
Stock/Commodities & 185 & 98.4 & 1.6 & \\
Markets & & & 0.0 & \\
Other & 11 & 100.0 & & \\
\hline
\end{tabular}

Table 7 presents indicators of the past year's gambling behavior of respondents grouped to each category of both the lifetime and current SOGS. While there are no consistent differences in who respondents gambled with respondents scoring in the problem categories of the SOGS are more likely to report playing for longer than three hours at a time and losing more than $\$ 100$ at a sitting. 
Table 7. Gamblers’ Past Year's Usual Gambling Behaviors by SOGS Scores, Percent Distributions

\begin{tabular}{|c|c|c|c|c|c|c|}
\hline & \multicolumn{3}{|c|}{ Lifetime SOGS } & \multicolumn{3}{|c|}{ Past Year SOGS } \\
\hline & $0-2$ & $3-4$ & $5+$ & $0-2$ & $3-4$ & $5+$ \\
\hline $\begin{array}{l}\text { When you gamble, do } \\
\text { you usually do so... }\end{array}$ & & & & & & \\
\hline Alone & 24.7 & 25.0 & 30.8 & 24.6 & 36.4 & 33.3 \\
\hline With spouse or partner & 29.2 & 37.5 & 20.8 & 29.5 & 27.3 & 11.1 \\
\hline $\begin{array}{r}\text { With other family } \\
\text { members }\end{array}$ & 14.1 & 8.3 & 7.7 & 13.9 & 9.1 & 11.1 \\
\hline With friends & 22.9 & 29.2 & 23.1 & 23.0 & 27.3 & 33.3 \\
\hline With coworkers & 3.8 & 0.0 & 0.0 & 3.7 & 0.0 & 00.0 \\
\hline With others & 5.3 & 0.0 & 7.7 & 5.3 & 0.0 & 11.1 \\
\hline $\mathrm{N}$ & 733 & 24 & 13 & 753 & 11 & 9 \\
\hline $\begin{array}{l}\text { When you gamble, do } \\
\text { you usually do so for... } \\
<1 \text { hour }\end{array}$ & 51.1 & 12.0 & 7.7 & 50.1 & 10.0 & 14.3 \\
\hline 1-2 hours & 30.5 & 44.0 & 38.5 & 31.0 & 30.0 & 42.9 \\
\hline 3-5 hours & 15.9 & 40.0 & 38.5 & 16.4 & 50.0 & 42.9 \\
\hline 6-12 hours & 1.3 & 4.0 & 7.7 & 1.3 & 10.0 & 0.0 \\
\hline$<12$ hours & 1.1 & 0.0 & 7.7 & 1.2 & 0.0 & 0.0 \\
\hline $\mathrm{N}$ & 741 & 25 & 13 & 761 & 10 & 7 \\
\hline $\begin{array}{l}\text { In the past year, what } \\
\text { is the largest amount } \\
\text { of money you have } \\
\text { ever lost gambling in } \\
\text { one day? }\end{array}$ & & & & & & \\
\hline$<\$ 1$ & 20.2 & 8.3 & 0.0 & 20.1 & 0.0 & 0.0 \\
\hline$\$ 1-\$ 9$ & 25.0 & 8.3 & 0.0 & 24.6 & 0.0 & 0.0 \\
\hline \$10-\$99 & 42.5 & 45.8 & 23.1 & 42.6 & 40.0 & 22.2 \\
\hline$\$ 100-\$ 999$ & 11.8 & 37.5 & 53.8 & 12.1 & 60.0 & 55.6 \\
\hline$\$ 1,000-\$ 9,999$ & 0.3 & 0.0 & 15.4 & 0.4 & 0.0 & 11.1 \\
\hline$\$ 10,000$ or more & 0.1 & 0.0 & 7.7 & 0.1 & 0.0 & 11.1 \\
\hline $\mathrm{N}$ & 731 & 24 & 13 & 751 & 10 & 9 \\
\hline
\end{tabular}




\section{$\underline{\text { Results for Problem Gamblers }}$}

Table 8 displays results for those respondents who scored as having a problem on the Lifetime SOGS. Estimates are provided here to enable comparison with the estimates reported in 1997, 1999, and 2001. The 1999 estimates were based on very small samples that suggested the oversampling of problem and probable pathological gamblers used subsequently. The first panel of Table 8 displays results from the representative sample. Recall that this sample contains 39 Lifetime problem and probable pathological gamblers (with 18 of these so scoring for the past year). Sampling errors are much larger here (estimates are not very precise ${ }^{4}$ ), since such a small number of respondents fell in these categories, especially on contingency questions (questions which are answered only for those who answer an entry question in a particular way). Panel B is based on the full set of 206 respondents who scored in the problem or probable pathological categories.

Both panels of Table 8 list important descriptive information for respondents who scored as problem or probable pathological gamblers on the Lifetime SOGS. Differences in the age at which a respondent first gambled are not apparent in either panel and for both lifetime and current contrasts. As expected and reported in our previous studies, larger percentages of probable pathological gamblers than problem gamblers report that the amount they were gambling has made them nervous. It is interesting that while the percentages of probable pathological gamblers who have desired to stop tend to be higher than for problem gamblers the percentages who have actually sought help is not dramatically different. Furthermore and more importantly, both groups have very low rates of seeking help. Thoughts of suicide related to gambling were reported by low percentages though, of course, even one such response is troubling. Finally, as before, a small but noticeable percentage of people who score as having a gambling problem also report a substance abuse or mental health problem.

\footnotetext{
${ }^{4}$ I.e., Another survey sample of this same size might yield a much larger or smaller value of the estimate.
} 
Table 8. Percentages of Problem and Probable Pathological Gamblers for Selected Characteristics

A: Representative Sample

\begin{tabular}{|c|c|c|c|c|c|}
\hline & \multicolumn{2}{|c|}{ Life Time SOGS } & & \multicolumn{2}{|c|}{ Past Yr/Current SOGS } \\
\hline & $3-4$ & $5+$ & & $3-4$ & $5+$ \\
\hline Age First Gambled & & & & & \\
\hline 14 or younger & 6.3 & 14.3 & & 0.0 & 0.0 \\
\hline $15-18$ & 37.5 & 42.9 & & 28.6 & 57.1 \\
\hline $19-29$ & 37.5 & 28.6 & & 57.1 & 28.6 \\
\hline 30 or older & 18.8 & 14.3 & & 14.3 & 14.3 \\
\hline$(n=30)$ & (16) & (14) & $(n=14)$ & (7) & (7) \\
\hline Has Gambling & 24.0 & 53.8 & & 40.0 & 50.0 \\
\hline $\begin{array}{l}\text { Made you Nervous } \\
\qquad(\mathrm{n}=38) \\
\text { Age Made } \\
\text { Nervous }\end{array}$ & (25) & (13) & $(n=18)$ & $(10)$ & (8) \\
\hline 14 or younger & 0.0 & 0.0 & & 0.0 & 0.0 \\
\hline $15-18$ & 16.7 & 16.7 & & 33.3 & 0.0 \\
\hline 19-29 & 83.3 & 33.3 & & 66.7 & 50.0 \\
\hline 30 or older & 0.0 & 50.0 & & 0.0 & 50.0 \\
\hline$(n=12)$ & (6) & (6) & $(n=7)$ & (3) & (4) \\
\hline Desired to Stop & 4.0 & 23.1 & & 0.0 & 22.2 \\
\hline$(n=38)$ & (25) & (13) & $(n=18)$ & (9) & (9) \\
\hline Sought Help & 0.0 & 7.7 & & 0.0 & 12.5 \\
\hline$(n=38)$ & (25) & (13) & $(n=17)$ & (9) & (8) \\
\hline Had Suicidal & 0.0 & 7.1 & & 0.0 & 12.5 \\
\hline$(n=39)$ & (25) & (14) & $(n=17)$ & (9) & (8) \\
\hline $\begin{array}{l}\text { Experience or } \\
\text { Treatment }\end{array}$ & & & & & \\
\hline $\begin{array}{l}\text { Alcohol or other } \\
\text { drug abuse } \\
\text { problem }\end{array}$ & 7.7 & 15.4 & & 10.0 & 22.2 \\
\hline$(n=39)$ & (26) & (13) & $(n=19)$ & (10) & (9) \\
\hline $\begin{array}{l}\text { Mental Health } \\
\text { Problem }\end{array}$ & 15.4 & 21.4 & & 11.1 & 25.0 \\
\hline$(n=39)$ & (26) & (14) & $(n=17)$ & (9) & (8) \\
\hline
\end{tabular}


B: Sample of Problem Gamblers

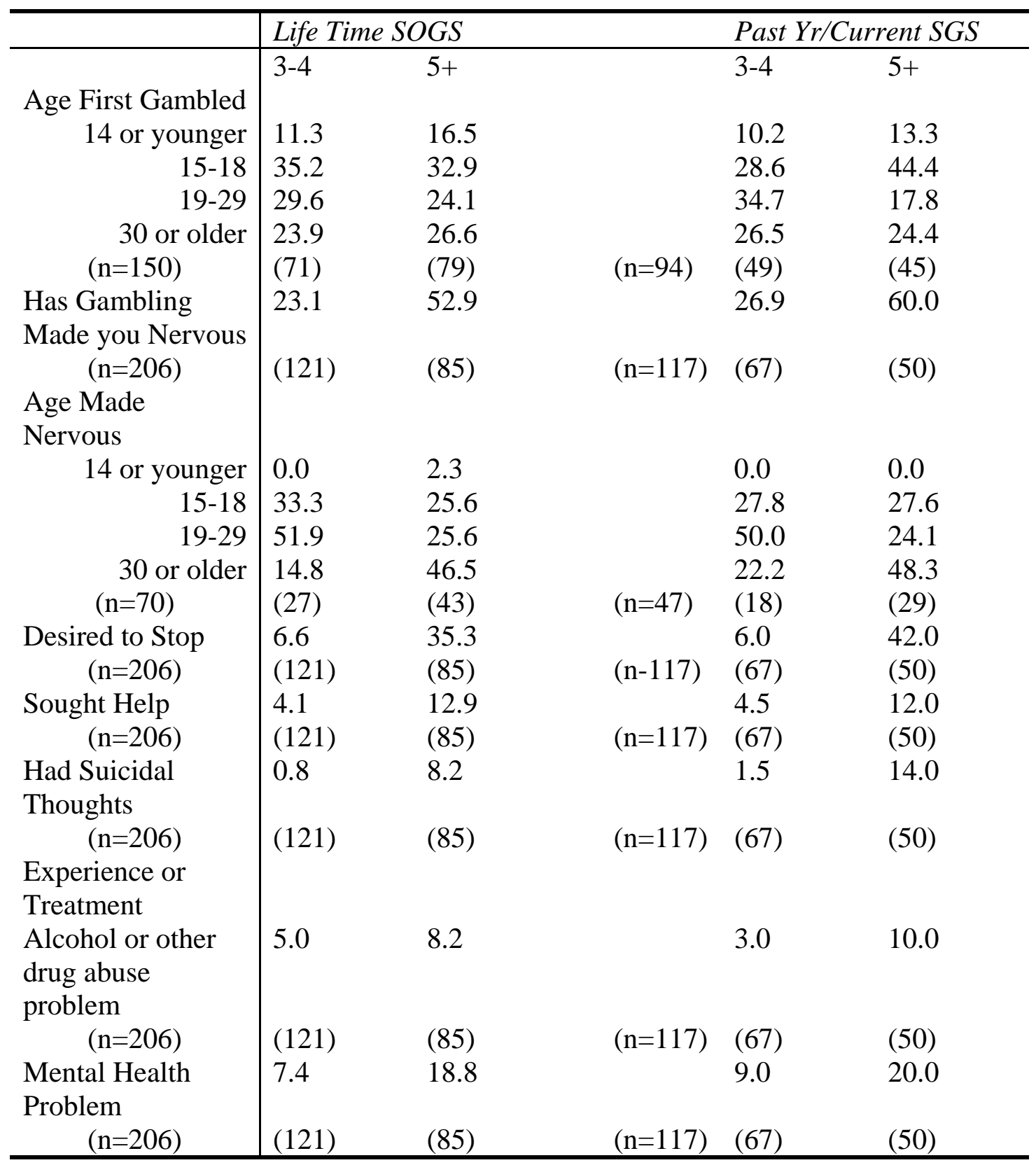


Summary

The statewide and regional rates of problem gambling and the more detailed presentations of gambling types, demographic correlates of activity, and the behaviors of gamblers present a relatively consistent story over the four Michigan surveys. As a set, they provide one important part of the available evidence on the nature and scope of gambling in Michigan.

The estimates of the gambling behavior of Michigan adults 18 years and older, provided in this report are based on what the authors believe are the best survey results available. We also believe there are weaknesses in this data set as in the results of any such survey. The poorest of our residents are more likely to live without regular phone service. If their gambling behavior is different from that of other residents, it is not fairly captured here. As we have said in the past, this effect is probably small however.

A more important problem is response bias among those we attempted to contact. While it is not clear that nonresponse is systematically related to the behaviors detailed in this survey, it is at least a good possibility that our estimates are conservative (underestimate the actual rates of problems). Youth and poverty are related to low response and, at least in many data sets, to problem gambling (though the income effect, in particular, is not always clear). A social desirability response might also suggest under-reporting or even refusal to participate for problem gamblers. Undoubtedly, much of the nonresponse was for reasons unrelated to gambling behavior, reasons such as an unwillingness to give the time required to respond to the survey. Nevertheless, as response rates decline in telephone surveys, concern over bias increases.

Another reason to believe our estimates may be conservative is the SOGS itself. In a cross-validation of the SOGS, it was found to provide a conservative estimate of probable pathological gamblers, probably around 6 percent (Lesieur and Blume 1987).

The stability of statewide problem estimates after the casino openings in Detroit is heartening but one should also recall that the rates in Detroit itself were quite high. Internet gambling remained small in this survey but seems likely to increase. Whether in casinos or home computers, access is presumed to affect the prevalence of gambling. The magnitude of 
such effects should be discernable over time.

In addition to these major findings, there is a wealth of detailed information to be found in the tables in this report. A useful strategy for understanding results, as we showed in Table 2 for example, is to convert the survey percentages to estimated population figures. The procedure for making this conversion is to take the point estimate from the table, e.g., the percentage of respondents reporting they played the lottery in the past year (Table 4, Panel B: point estimate is 50.6 percent), and multiply by the estimated adult population of Michigan $(7,342,677)$ to get an estimate of 3,715,395 adult lottery players. This can also be done for the point estimates that make up the lower and upper bounds of the confidence intervals, which would yield an estimated range for the population figures. A similar procedure for problem gamblers would be to take the point or interval estimates for the representative sample of problem gamblers (remember, though much larger in this study at over 200, this sample is still small and therefore yields imprecise estimates) and multiply by the estimated number of adult problem gamblers from Table 2. One should always remember the cautions we have made about response bias and a probable underestimation of many gambling behaviors.

In the context of this report we can only suggest the range of analysis and discussion that these data will support. And we must also note that this richness is multiplied when this study is added to the baseline established in 1997 and the work completed in 1999 and 2001. The general lesson is consistent across our studies and so we repeat our conclusion: "Estimates continue to suggest that problem gambling is a substantial reality in Michigan and reaches across demographic and geographic boundaries. Perhaps most telling is that even among persons scoring as problem or probable pathological gamblers, rates of help seeking are very low. All of this reinforces the obligation to continue to systematically collect data on gambling so that the public discussion may be as balanced and informed as possible.” 
Appendix A:

\section{SURVEY INSTRUMENT}

Introduction: (purposes, sponsors, rights of refusal, protections, numbers to call for additional information)

People spend or bet money on a variety of things including lottery, charitable games such as raffles or church sponsored bingo, horse races, casinos, sports, cards and dice.

We will ask you about whether you have ever participated in these activities and whether you have participated in the past 12 months. We will ask about the extent of your participation and how gambling affects other aspects of your life. You may prefer to keep some of your answers private from people who could overhear this interview.

May we continue?

[We understand that not everyone gambles, but your opinions are still very important to us.]

1. Have you ever bet or spent money on the Lottery including LOTTO, The Big Game, Daily 3 and 4, Cash 5, Keno, or instant tickets?

Yes (skips to 1a)

No (skips to 2)

Don't know/Refused (skips to 2)

1a. Have you done so in the past year?

Yes

No

Don't know/Refused

2. Have you ever bet on charitable group events such as local bingos, pulltab tickets, Las Vegas Nights, or raffles?

Yes (skips to 2a)

No (skips to 3)

Don't know/Refused (skips to 3)

2a. Have you done so in the past year?

Yes

No

Don't know/Refused 
3. Have you ever bet on the outcome of sports events?

Yes (skips to 3a)

No (skips to 4)

Don't know/Refused (skips to 4)

3a. Have you done so in the past year?

Yes

No

Don't know/Refused

4. Have you ever bet on horse or dog racing?

Yes (skips to 4a)

No (skips to 5)

Don't know/Refused (skips to 5)

4a. Have you done so in the past year?

Yes

No

Don't know/Refused

5. Have you ever bet or spent money on a numbers game not sponsored by the state lottery?

Yes (skips to 5a)

No (skips to 6)

Don't know/Refused (skips to 6)

5a. Have you done so in the past year?

Yes

No

Don't know/Refused

6. Have you ever bet at casinos (including slots, video machines, and table games)?

Yes (skips to 6a)

No (skips to 7)

Don't know/Refused (skips to 7)

6a. Have you done so in the past year?

Yes

No

Don't know/Refused

7. Have you ever played non-charitable Bingo for money?

Yes (skips to 7a)

No (skips to 8)

Don't know/Refused (skips to 8)

7a. Have you done so in the past year?

Yes

No

Don't know/Refused 
8. Have you ever bet on cards or dice games or on video poker or other machines not at a casino?

Yes (skips to 8a)

No (skips to 9)

Don't know/Refused (skips to 9)

8a. Have you done so in the past year?

Yes

No

Don't know/Refused

9. Have you ever bet on your performance at games of skill such as pool, golf, bowling, darts or other games?

Yes (skips to 9a)

No (skips to 10)

Don't know/Refused (skips to 10)

9a. Have you done so in the past year?

Yes

No

Don't know/Refused

10. Have you ever bet in office pools or 50/50 raffles?

Yes (skips to 10a)

No (skips to $11 \mathrm{x}$ )

Don't know/Refused (skips to 11x)

10a. Have you done so in the past year?

Yes

No

Don't know/Refused

11x. Have you ever bet money at internet gambling sites?

Yes (skips to 11y)

No (skips to 11)

Don't know/Refused (skips to 11)

$11 y$. Have you done so in the past year?

Yes

No

Don't know/Refused

11. Have you ever bet or spent money on the stock or commodities markets?

Yes (skips to 11a)

No (skips to 12)

Don't know/Refused (skips to 12)

11a. Have you done so in the past year?

Yes

No

Don't know/Refused 
12. Have you bet or spent money on any other type of gambling?

Yes (skips to 12a)

No (skip to 13)

Don't know/Refused (skips to 13)

12a. Have you done so in the past year?

Yes

No

Don't know/Refused

IF "NO" OR "DON'T KNOW/REFUSED" TO ALL GAMBLING ACTIVITIES, SKIP TO SECTION 4: DEMOGRAPHICS.

13. When you gamble, do you usually do so ...

Alone

With your spouse or partner

With other family members

With friends

With co-workers

With some other individual or group

DK/Refused

14. When you gamble, do you usually do so for ...

Less than 1 hour

1-2 hours

3-5 hours 4. 6-12 hours

More than 12 hours

DK/Refused

15. In the past year, what is the largest amount of money you have ever lost gambling in one day?

Less than $\$ 1$

$\$ 1-\$ 9$

$\$ 10-\$ 99$

$\$ 100-\$ 999$

$\$ 1,000$ - $\$ 9,999$

$\$ 10,000$ or more

DK/Refused

\section{SECTION 2: SOUTH OAKS GAMBLING SCREEN}

The next set of questions is part of a standard measurement scale that has been used throughout the United States in surveys similar to this one. There are no right or wrong answers to the questions that follow. We want to know what your experiences have been. Please try to be as accurate as possible in your answers and remember that all this information is confidential. [INTERVIEWER: IF YOU ENCOUNTER DIFFICULTIES WITH RESPONDENTS IN COMPLETING THIS SECTION, SAY: "We realize these question may not apply to everyone, but we would like answers to any of the questions you may choose to answer."] 
16A. When you participate in the gambling activities we have discussed, how often do you go back another day to win back money you lost? Is it:

Never (skips to 17A)

Some of the time

Most of the time (SOGS=1)

Every time (SOGS=1)

Don't know/Refused (skips to 17A)

16B. How often have you done this in the past year?

Never

Some of the time

Most of the time

Every time

Don't know/Refused

17A. Have you ever claimed to be winning money from these activities when in fact you lost?

Never (skips to 18A)

Some of the time $(\mathrm{SOGS}=1)$

Most of the time (SOGS=1)

Every time (SOGS=1)

Don't know/Refused (skips to 18A)

17B. How often have you done this in the past year?

Never

Some of the time

Most of the time

Every time

Don't know/Refused

18A. Do you ever spend more time or money gambling than you intended?

Yes $(\mathrm{SOGS}=1)$

No (skips to 19A)

Don't know/Refused (skips to 19A)

18B. Have you done this in the past year?

Yes

No

Don't know/Refused

19A. Have people ever criticized your gambling?

Yes (SOGS $=1$ )

No (skips to 20A)

Don't know/Refused (skips to 20A)

19B. Have people criticized your gambling in the past year?

Yes

No

Don't know/Refused 
20A. Have you ever felt guilty about the way you gamble or about what happens when you gamble?

Yes (SOGS=1)

No (skips to 21A)

Don't know/Refused (Skip to 21A)

20B. Have you felt this way in the past year?

Yes

No

Don't know/Refused

21A. Have you ever felt that you would like to stop gambling, but didn't think that you could?

Yes (SOGS=1)

No (skips to 22A)

Don't know/Refused (skips to 22A)

21B. Have you felt this way in the past year?

Yes

No

Don't know/Refused

22A. Have you ever hidden betting slips, lottery tickets, gambling money or other signs of gambling from your spouse or partner, children, or other important people in your life? Yes (SOGS=1)

No (skips to 23)

Don't know/Refused (skips to 23)

22B. Have you done so in the past year?

Yes

No

Don't know/Refused

23. Have you ever argued with people you live with over how you handle money?

Yes

No (skips to 25A)

Don't know/Refused (skips to 25A)

24A. Have these arguments ever centered on your gambling?

Yes (SOGS $=1$ )

No (Skips to 25A)

Don't know/Refused (Skips to 25A)

24B. Have you had any of these arguments in the past year?

Yes

No

Don't know/Refused 
25A. Have you ever missed time from work or school due to gambling?

Yes $(\mathrm{SOGS}=1)$

No (skips to 26A)

Don't know/Refused (skips to 26A)

25B. Have you missed time from work or school in the past year due to gambling?

Yes

No

Don't know/Refused

26A. Have you ever borrowed money from someone and not paid them back as a result of your gambling?

Yes $(\mathrm{SOGS}=1)$

No (skips to 27A)

Don't know/Refused (skips to 27A)

26B. Have you done so in the past year?

Yes

No

Don't know/Refused

Next, I am going to read a list of ways in which some people get money for gambling. Can you tell me which of these, if any, you have ever used to get money for gambling or to pay gambling debts?

27A. Have you ever borrowed from household money to gamble or pay gambling debts?

Yes (SOGS=1)

No (skips to 28A)

Don't know/Refused (skips to 28A)

27B. Have you borrowed from household money in the past year?

Yes

No

Don't know/Refused

28A. Have you ever borrowed money from your spouse or partner to gamble or pay gambling debts?

Yes $(\mathrm{SOGS}=1)$

No (skips to 29A)

Don't know/Refused (skips to 29A)

28B. Have you borrowed money from your spouse or partner in the past year?

Yes

No

Don't know/Refused

29A. Have you ever borrowed from other relatives or in-laws to gamble or pay gambling debts?

Yes (SOGS=1)

No (skips to 30A)

Don't know/Refused (skips to 30A) 
29B. Have you borrowed from other relatives or in-laws in the past year?

Yes

No

Don't know/Refused

30A. Have you ever gotten loans from banks, loan companies or credit unions to gamble or pay gambling debts?

Yes (SOGS=1)

No (skips to 31A)

Don't know/Refused (skips to 31A)

30B. Have you gotten loans from banks, loan companies or credit unions in the past year?

Yes

No

Don't know/Refused

31A. Have you ever made cash withdrawals on credit cards to get money to gamble or pay gambling debts? [DOES NOT INCLUDE INSTANT CASH CARDS FROM BANK ACCOUNTS]

Yes $(\mathrm{SOGS}=1)$

No (skips to 32A)

Don't know/Refused (skips to 32A)

31B. Have you made cash withdrawals on credit cards in the past year?

Yes

No

Don't know/Refused

32A. Have you ever gotten loans from loan sharks to gamble or pay gambling debts?

Yes $(\mathrm{SOGS}=1)$

No (skips to 33A)

Don't know/Refused (skips to 33A)

32B. Have you gotten loans from loan sharks in the past year?

Yes

No

Don't know/Refused

33A. Have you ever cashed in stocks, bonds or other securities to finance gambling?

Yes (SOGS $=1$ )

No (skips to 34A)

Don't know/Refused (skips to 34A)

33B. Have you cashed in stocks, bonds or other securities in the past year?

Yes

No

Don't know/Refused 
34A. Have you ever sold personal or family property to gamble or pay gambling debts?

Yes $(\mathrm{SOGS}=1)$

No (skips to 35A)

Don't know/Refused (skips to 35A)

34B. Have you sold personal or family property to gamble or pay gambling debts in the past year?
Yes
No
Don't know/Refused

35A. Have you ever borrowed from your checking account by writing checks that bounced to get money for gambling or to pay gambling debts?

Yes (SOGS=1)

No (skips 36A)

Don't know/Refused (skips to 36A)

35B. Have you borrowed from your checking account by writing checks that bounced in the past year?

Yes

No

Don't know/Refused

36A. Have you ever delayed or missed payments on insurance policies, such as life, car, household or medical insurance, to get money to gamble or pay gambling debts?

Yes

No (skips to 37A)

Don't know/Refused (skips to 37A)

36B. Have you delayed or missed payments on insurance policies to gamble or pay gambling debts in the past year?
Yes
No
Don't know/Refused

37A. Have you ever cashed in life insurance premiums to get money to gamble or pay for gambling debts?

Yes

No (skips to 38A)

Don't know/Refused (skips to 38A)

37B. Have you cashed in life insurance premiums to get money to gamble or pay for gambling debts in the past year?

Yes

No

Don't know/Refused 
38A. Do you feel that you have ever had a problem with betting money or gambling?

Yes (SOGS=1)

No (skips to 39A)

Don't know/Refused (skips to 39A)

38B. Do you feel that you have had a problem with betting money or gambling in the past year?

Yes

No

Don't know/Refused

39. Do you feel that either of your parents ever had a problem with betting money or gambling?

Yes

No*

Don't know/Refused*

*skips to 40A if SOGS score is 3 or more or to 73 if SOGS score is less than 3.

39A. Which parent was that? [Select all that apply]

Father

Mother

Stepfather

Stepmother

No More Apply/Refused

(skips to 40A if SOGS score is 3 or more or to 73 if SOGS score is less than 3 )

SECTION 3: IN-DEPTH ANALYSIS OF PROBLEM GAMBLERS

Ask Section 3 only of those who score as Problem Gamblers on the SOGS (generated by the computer). The skip pattern is based on the responses to questions 1 through 12 .

For each of the gambling activities in which you participated in the past year, we would like your estimate of the amount of time and money you spent.

[INTERVIEWER: If needed, say ... "I am only looking for an approximate amount, rounded to the nearest 5 dollars or so."]

40A. For the Lottery (LOTTO, Big Game, Daily 3 and 4, Cash 5, Keno, or instant tickets, can you give me an estimate of the amount you spend in a typical month?

40B. Did you play the lottery at least once a week?

Yes

No

Don't know/Refused

41A. For charitable group events, such as bingo or Las Vegas nights, can you give me an estimate of the amount you spend in a typical month? 
41B. Did you play charitable group events at least once a week?

Yes

No

Don't know/Refused

42A. For sports betting, can you give me an estimate of the amount you spend in a typical month?

42B. Did you bet on sports at least once a week?

Yes

No

Don't know/Refused

43A. For betting on horse or dog racing, can you give me an estimate of the amount you spend in a typical month?

43B. Did you bet on horse or dog racing at least once a week?

Yes

No

Don't know/Refused

44A. For non-Lottery numbers games, can you give me an estimate of the amount you spend in a typical month?

44B. Did you play non-Lottery numbers or policy at least once a week?

Yes

No

Don't know/Refused

45A. For betting at casinos, can you give me an estimate of the amount you spend in a typical month?

45B. Did you bet at casinos at least once a week?

Yes

No

Don't know/Refused

46A. For playing non-charitable Bingo for money, can you give me an estimate of the amount you spend in a typical month?

46B. Did you play non-charitable Bingo for money at least once a week?

Yes

No

Don't know/Refused 
47A. For cards, dice, video poker or other machine games not in a casino, can you give me an estimate of the amount you spend in a typical month?

47B. Did you bet on cards, dice, video poker or other machine games not in a casino at least once a week?
Yes
No
Don't know/Refused

48A. For betting on your performance at games of skill like pool, golf, bowling, or darts, can you give me an estimate of the amount you spend in a typical month?

48B. Did you bet on your performance at games of skill at least once a week?

Yes

No

Don't know/Refused

49A. For office pools or 50/50 raffles, can you give me an estimate of the amount you spend in a typical month?

49B. Did you bet on office pools or 50/50 raffles at least once a week?

\section{Yes}

No

Don't know/Refused

50A. For Internet gambling, can you give me an estimate of the amount you spend in a typical month?

50B. Did you bet at Internet gambling sites at least once a week?

Yes

No

Don't know/Refused

51A. For the stock or commodities markets, can you give me an estimate of the amount you spend in a typical month?

51B. Did you play the stock or commodities markets at least once a week?

Yes

No

Don't know/Refused

52A. For other types of gambling, can you give me an estimate of the amount you spend in a typical month? 
52B. Did you bet on other forms of gambling at least once a week?

Yes

No

Don't know/Refused

62. Which type of gambling would you find most difficult to give up? [Choose only one; read list if necessary; i.e., respondent hesitates.]

The Lottery (LOTTO, Big Game, Daily 3 and 4, Cash 5, Keno, etc.)

Charitable group events (bingo, pulltab tickets, Las Vegas Nights, raffles)

The outcome of sports events

Horse or dog racing

A numbers game not sponsored by the state lottery

Casinos (including slots, video machines, and table games)

Playing non-charitable Bingo for money

Cards or dice games or video poker or other machines not at a casino

Your performance at games of skill (pool, golf, bowling, darts, etc.)

Office pools or $50 / 50$ raffles

Internet gambling sites

Playing the stock or commodities markets

Other (Please specify).

Don't Know/Refused/No More Apply

B. History and Treatment

63. How old were you when you first gambled?

64. What type of gambling was that? [Choose only one]

The Lottery (LOTTO, Big Game, Daily 3 and 4, Cash 5, Keno, etc.)

Charitable group events (bingo, pulltab tickets, Las Vegas Nights, raffles)

The outcome of sports events

Horse or dog racing

A numbers game not sponsored by the state lottery

Casinos (including slots, video machines, and table games)

Playing non-charitable Bingo for money

Cards or dice games or video poker or other machines not at a casino

Your performance at games of skill (pool, golf, bowling, darts, etc.)

Office pools or $50 / 50$ raffles

Internet gambling sites

Playing the stock or commodities markets

Other (Please specify)

Don't Know/Refused

65. Was there any time when the amount you were gambling made you nervous?

Yes

No (skips to 68)

Don't know/Refused (skips to 68)

66. How old were you when that happened? 
67. What type of gambling were you doing when that happened? (Choose only one)

The Lottery (LOTTO, Big Game, Daily 3 and 4, Cash 5, Keno, etc.)

Charitable group events (bingo, pulltab tickets, Las Vegas Nights, raffles)

The outcome of sports events

Horse or dog racing

A numbers game not sponsored by the state lottery

Casinos (including slots, video machines, and table games)

Playing non-charitable Bingo for money

Cards or dice games or video poker or other machines not at a casino

Your performance at games of skill (pool, golf, bowling, darts, etc.)

Office pools or 50/50 raffles

Internet gambling sites

Playing the stock or commodities markets

Other (Please specify)

Don't Know/Refused

68. Have you ever desired help to stop gambling?

Yes

No

Don't know/Refused

69. Have you ever sought help to stop gambling?

Yes

No

Don't know/Refused

70. What type of help was that? [Read list; mark all that apply]

Family member

Friend

Family doctor

Gamblers Anonymous/Gamanon

Problem gambling treatment program in Michigan

Employee assistance program (EAP)

Professional Counseling (Psychologist/Psychiatrist/Other counselor)

Minister/Priest/Rabbi/Imam (Muslem prayer leader)

Alcohol or drug abuse treatment program

Refused/No More Apply

70a. Have you ever called the State Problem Gambling Help Line (1-800-270-7117).

Yes

No

Don't know/Refused

70b. Have you ever experienced thoughts of suicide related to your gambling?

Yes

No

Don't know/Refused

C. Cross-Addictions 
71. Have you ever experienced or been treated for an alcohol or other drug abuse problem?

Yes

No

DK/Refused

72. Have you ever experienced or been treated for a mental health problem?

Yes

No

DK/Refused

\section{SECTION 4: DEMOGRAPHICS}

As you probably know, different types of people have different opinions and experiences. The following questions are for statistical purposes only and the answers to these questions, like all of the others, will be confidential.

73. Are you currently married, widowed, divorced, separated, or have you never been married?

Married, common-law, co-habitation

Widowed

Divorced

Separated

Never married

DK/Refused

74. Including yourself, how many people age 18 and over live in your household?

75. What is the last grade of school you completed?

Elementary or some high school

High school graduate or G.E.D.

Some college or Associates degree (vocational, technical or trade school)

Undergraduate degree

Graduate study or degree

DK/Refused

76. Last week, were you working full-time, part-time, going to school, keeping house, or something else? [Choose all that apply.]

Working full-time

Working part-time

Going to school

Keeping house

Disabled

Retired

Unemployed

Somthing else

No More Apply/Refused I:

77. What is your age? 
78. Do you consider yourself Hispanic?

Yes

No

Don't know/Refused

79. Which of the following best describes your racial or ethnic group?

White/Caucasian

Black/African American

Native American

Asian

Other

No opinion/Refused

80. What was your total household income last year?

Under $\$ 15,000$

$\$ 15,001$ to $\$ 25,000$

$\$ 25,001$ to $\$ 35,000$

$\$ 35,001$ to $\$ 50,000$

$\$ 50,001$ to $\$ 75,000$

$\$ 75,001$ to $\$ 100,000$

$\$ 100,001$ to $\$ 125,000$

Over $\$ 125,000$

Don't Know/Refused

81. In what county do you live?

82. Could I have the name of the city you live in or nearest to?

That was the last question. Thank you very much for your time and cooperation.

83. RESPONDENT'S SEX (DON'T ASK)

Male

Female

Cannot tell 
Appendix B:

\section{COUNTIES IN GEOGRAPHIC REGIONS}

1= City of Detroit

2= Detroit Metro Area (excluding Detroit)

Wayne County (excluding Detroit)

St. Clair

Lapeer

Macomb

Oakland

Livingston

Washtenaw

Monroe

3= East Region of the State

Cheboygan Bay Presque Isle

Huron

Montmorency

Otsego

Sanilac

Saginaw

Oscoda

Shiawassee

Tuscola

Alpena

Crawford

Gratiot

Clinton

Alcona

Ogemaw

Roscommon

Genesee

Ingham

Eaton

Iosco

Gladwin

Clare

Hillsdale

Lenawee

Isabella

Jackson

Arenac

Midland

4= West Region of the State

$\begin{array}{lll}\text { Emmet } & \text { St. Joseph } & \text { Charlevoix } \\ \text { Cass } & \text { Antrim } & \text { Berrien } \\ \text { Leelanau } & \text { Van Buren } & \text { Benzie } \\ \text { Kalamazoo } & \text { Grand Traverse } & \text { Kalkaska } \\ \text { Manistee } & \text { Wexford } & \text { Missaukee } \\ \text { Mason } & \text { Lake } & \text { Osceola } \\ \text { Oceana } & \text { Newaygo } & \text { Mecosta } \\ \text { Montcalm } & \text { Ionia } & \text { Kent } \\ \text { Ottawa } & \text { Muskegon } & \text { Allegan } \\ \text { Barry } & \text { Calhoun } & \text { Branch }\end{array}$

5= Upper Peninsula

Delta

Schoolcraft

Mackinac

Chippewa

Luce

Alger

Menominee

Dickinson

Marquette

Iron

Baraga

Houghton

Keweenaw

Ontonagon

Gogebic 


\section{References}

American Psychiatric Association. (1987). Diagnostic and statistical manual of mental disorders (3rd ed.-rev). Washington, DC: Author.

Blalock, H.M. (1979). Social Statistics, Revised $2^{\text {nd }}$ edition. New York: McGraw-Hill.

British Columbia Problem Gambling Prevalence Study. (2003). Ministry of Public Safety and Solicitor General.

Groves, R., Fowler, F.J., Couper, M.P., Lepkowski, J.M., Singer, E., and Tourangeau, R. (2004). Survey Methodology. Hoboken: Wiley.

Gullickson, A. and Hartmann, D.J. (1997). Compulsive Gambling in Michigan: Final Report. A report to the Bureau of State Lottery. Kalamazoo: The Evaluation Center in collaboration with the Leonard C. Kercher Center for Social Research.

Hartmann, D.J., Gullickson, A., and Wiersma, W. (1999). A Survey of Gambling Behaviors in Michigan, 1999. A report to the Michigan Department of Community Health. Kalamazoo: Evaluation Center and Kercher Center for Social Research.

Hartmann, D.J., and Gullickson, A. (2001). A Survey of Gambling Behaviors in Michigan, 2001. A report to the Michigan Department of Community Health. Kalamazoo: The Evaluation Center in conjunction with the Kercher Center for Social Research.

Lesieur, H. R., \& Blume, S. (1987) . The South Oaks gambling screen (SOGS): A new instrument for the identification of pathological gamblers. American Journal of Psychiatry, 144(9), 1184-1.

United States Census (1998). Population Estimates for the U.S., Regions, and States by Selected Age Groups and Sex: Annual Time Series, July 1, 1990 to July 1, 1998. (www.census.gov/population/estimates/state/sage9890.txt).

Volberg, R. A. (1995a). Gambling and problem gambling in Georgia. (Report to the Georgia Department of Human Resources). Roaring Spring, PA: Gemini Research.

Volberg, R. A. (1995b). Gambling and problem gambling in Iowa: A replication survey. (Report to the Iowa Department of Human Services, Division of Mental Health and Developmental Disabilities, Gambling Treatment Program). Des Moines: Iowa Department of Human Services.

Volberg, R. A. (1996a). Prevalence studies of problem gambling in the United States. Journal of Gambling Studies, 12 (12), 111-128.

Volberg, R. A. (1996b). Wagering and problem wagering in Louisiana. (Report to the Louisiana Economic Development \& Gaming Corporation). Roaring Spring, PA: Gemini Research. 
Volberg, R. A. (1996c). Gambling and problem gambling in New York: A 10-year replication survey, 1986 to 1996. (Report to the New York Council on Problem Gambling). Roaring Spring, PA: Gemini Research.

Volberg, R. A. (2004). "Fifteen years of problem gambling prevalence research: What do we know? Where do we go?” Gambling: The Electronic Journal of Gambling Issues. (http://www.camh.net/egambling/issue10/ejgi_10_volberg.html). 